\title{
An Empirical Method for Calculating Stabilizing and Rotation Components Through Elbow Flexion
}

\author{
Mohamed Gaber Berequa*, Yasser Atif Ghoraba**, Wael Mohamed Abd El-Kader***
}

\section{Introdcution}

$M$ ost people use elbow flexion many times every day, whether through deliberate exercise or simply completing daily activities. A few examples of the many activities that typically requireelbow flexion are raising silverware to the mouth while eating, picking up and carrying an object close to the chest, or putting on a pair of glasses. Since activities that require elbowflexion are such a large part of most people's daily lives.

The elbow is a relatively simple hinge joint which only allows flexion and extension. This makes it quite a stable joint too ,An elbow flexion is a movement that occurs when the arm is bent at the elbow and the forearm and the upper arm come together.(6)

An elbow flexion is a movement that occurs when the arm is bent at the elbow and the forearm and the upper arm come together. This is the opposite of an elbow extension, during which the arm is straightened and the forearm and upper arm move away from one another. An alternate definition that is sometimes used clarifies that a flexion occurs when the angle of the joint decreases, so an elbow flexion occurs when the angle of the arm, with the elbow as a vertex.(18)

Forces are vectors with magnitudes and directions that can be analyzed into its perpendicular components. The ration of these two components to total force depends on

\footnotetext{
* Professor of Bio-Mechanics, Head of Kinematics Dept, Faculty of Physical Education, Tanta University, Egypt.

** Assistant Professor, Kinesiology Dept, Faculty of Physical Education, Tanta University, Egypt.

*** Teacher, Ministry of Education, Egypt.
}

deviation angle of the force vector,As for working muscles, tension angle is always changing due to the changes in the moving elbow angle. Therefore, the magnitudes of horizontal and vertical components are always changing as the muscle continues its contraction. This change in both components has two synchronized effects of tension forces over the moving limb (1)

Some authors think that the increase of rotation / moving component may be more effective in any performance. Nevertheless, it is noteworthy that stabilizing component is important for maintaining the joint shape and preventing injuries, especially in cases of strong quick muscle contraction of the shoulder, neck and elbow (2)

Under all conditions, we can say that muscular work has two synchronous functions, these are stabilization and rotation. The muscle role through its horizontal component of tension does not appear unless it move or any time that the joint formation unit is endangered for damage or disequilibrium (1)

The carrying angle orientation changes from a valgus orientation in extension to varus orientation in flexion. [For simplicity, one may assume that the ulnohumeral joint is a pure hinge joint, and that the axis of rotation coincides with the trochlea so that the change in carrying angle with flexion is caused by anatomic variations of the articulation.(5)

Each joint has an angle where working muscles are in its peak and vice versa as these muscles are in its maximal weakness. In the second case, the joint is more vulnerable for injury due to the weakness of its working muscles (3)

The elbow joint is one of the most important multi-use joints that is used in most motor 
performances of the upper limb with all its various forms.

Therefore, it is very important to identify the values of stabilization and rotation components during elbow flexion using a bio-mechanical model for calculating tension angles and identifying the best joint angles where working muscles are in it peak. This is to use these results in improving training outcomes and identifying weal angles to prevent injuries.

\section{This Study Aimed at Identifying the Following Objectives}

The current research aims at developing an empirical method for calculating the stabilization and rotation components of elbow flexion through:

1. Calculating tension angles of the working muscles in each position of elbow flexion

2. Calculating the stabilization and rotation components in each position of elbow flexion

3. Identifying the best joint angles for exerting maximal work during elbow flexion

4. Identifying the weakness angles where injury is most possible during elbow flexion

\section{Research questions:}

1. What are the values of tension angles of the working muscles in each position of elbow flexion?

2. What are the values of the stabilization and rotation components in each position of elbow flexion?

3. What are the best joint angles for exerting maximal work during elbow flexion?

4. What are the weakness angles where injury is most possible during elbow flexion?

\section{Definition of Terms:}

- Stabilization Component: It is the horizontal component, parallel with the longitudinal axis of the moving bone. If it works in the direction of rotation axis, it pulls the two joint bones towards each other and, therefore, helps joint ligaments to maintain its shape during movement. $(2,4)$
- Rotation Component: It is the vertical pulling component, perbendicular to the mechanical axis of the moving bone. It is part of the muscular force and responsible for rotating the joint. $(1,2,5)$

\section{Materials and Methods}

Participants The elbow joint flexion movement

\section{Procedures:}

Methods include five consecutive phases:

First Phase: It includes identifying research approach and sample

\section{Approach:}

The researchers used the descriptive approach.

Second Phase: Muscular motor analysis of elbow flexion

The researchers used the qualitative anatomical analysis (prepared by Mohamed Berequa)(6), Which have been applied in the study of Wael Abdul Qadir "Mechanics of the shoulder joint injuries in some Racket Sport players as a base of preventative training programs" Appling the qualitative anatomical analysis.( 8 ) to identify the working muscles. This led to identifying the following muscles:

Biceps Brachii

Brachialis

Brachio Radialis

Third Phase: Simulation and Photography

Simulation was performed using a biomechanical model - designed by the researchers - through fixing elbow angle on the model in a position similar to natural movement, according to angles needed to calculate tension angles and in the range of motion of the natural angle. Angle between the forearm and upper are bones ranged between $180^{\circ}$ and $30^{\circ}$,

The researcher used anatomical qualitative analysis method Experimental control The researcher conducted a pilot study to investigate the effectiveness of the biomechanical model that is used by the researcher. The researcher introduced the experiment to a group of Anatomy experts in 
the anatomy lab in the faculty of medicine to test the validity and reliability of the model The results of the pilot study-identifying the working muscles measuring the angles of each muscle by AutoCAD program.
Elbow angle was fixed on six positions on $180^{\circ}$, $150^{\circ}, 120^{\circ}, 90^{\circ}, 60^{\circ}$ and $30^{\circ}$ to calculate the stabilization and rotation components on each position.Then photography was taken for these positions.

Figure (1)

Scoping study in anatomy lab at the Faculty of Medicine
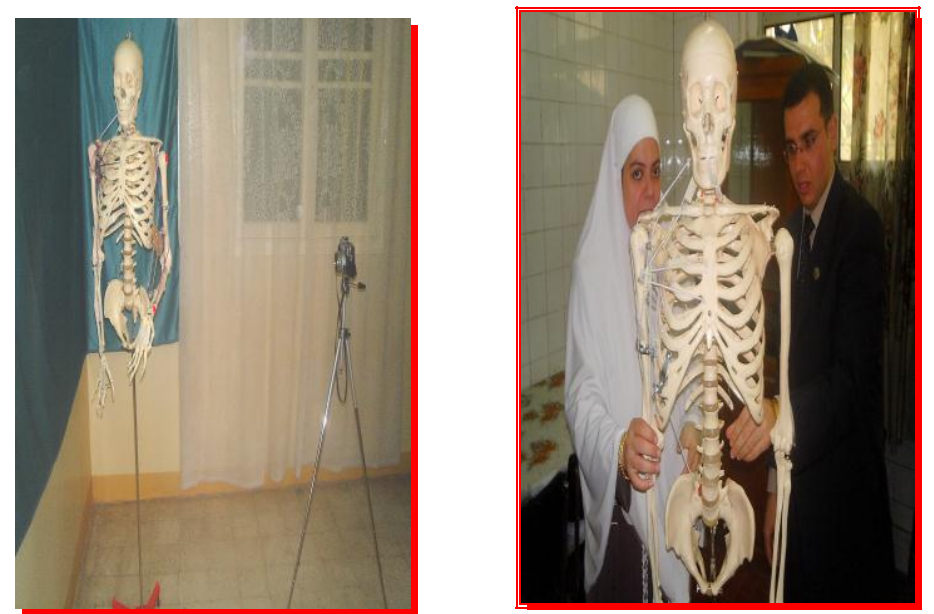

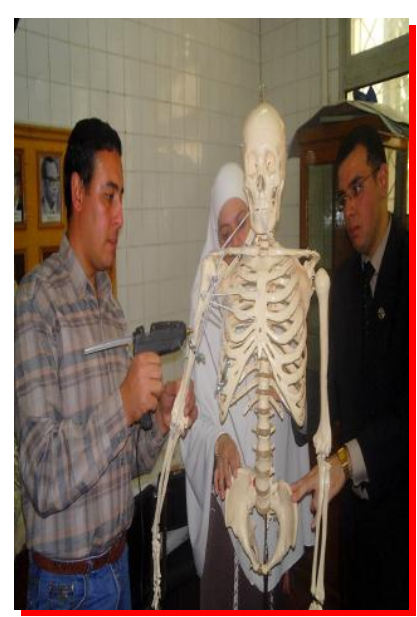

\section{Photography Procedures:}

1. Using a digital camera for facilitating photo input

2. Fixing the camera perpendicular to elbow joint and working muscles

3. Using a rear curtain with different color
4. Fixing numbers over the model that appear in each picture for cadre numbering

5. Using synthetic lights distributed to cover shadows

6. Shooting working muscles in these cadres to be discriminated through identifying its line of work, the moving bone and cadre number 
Figure (2)

Simulation of Elbow Flexion

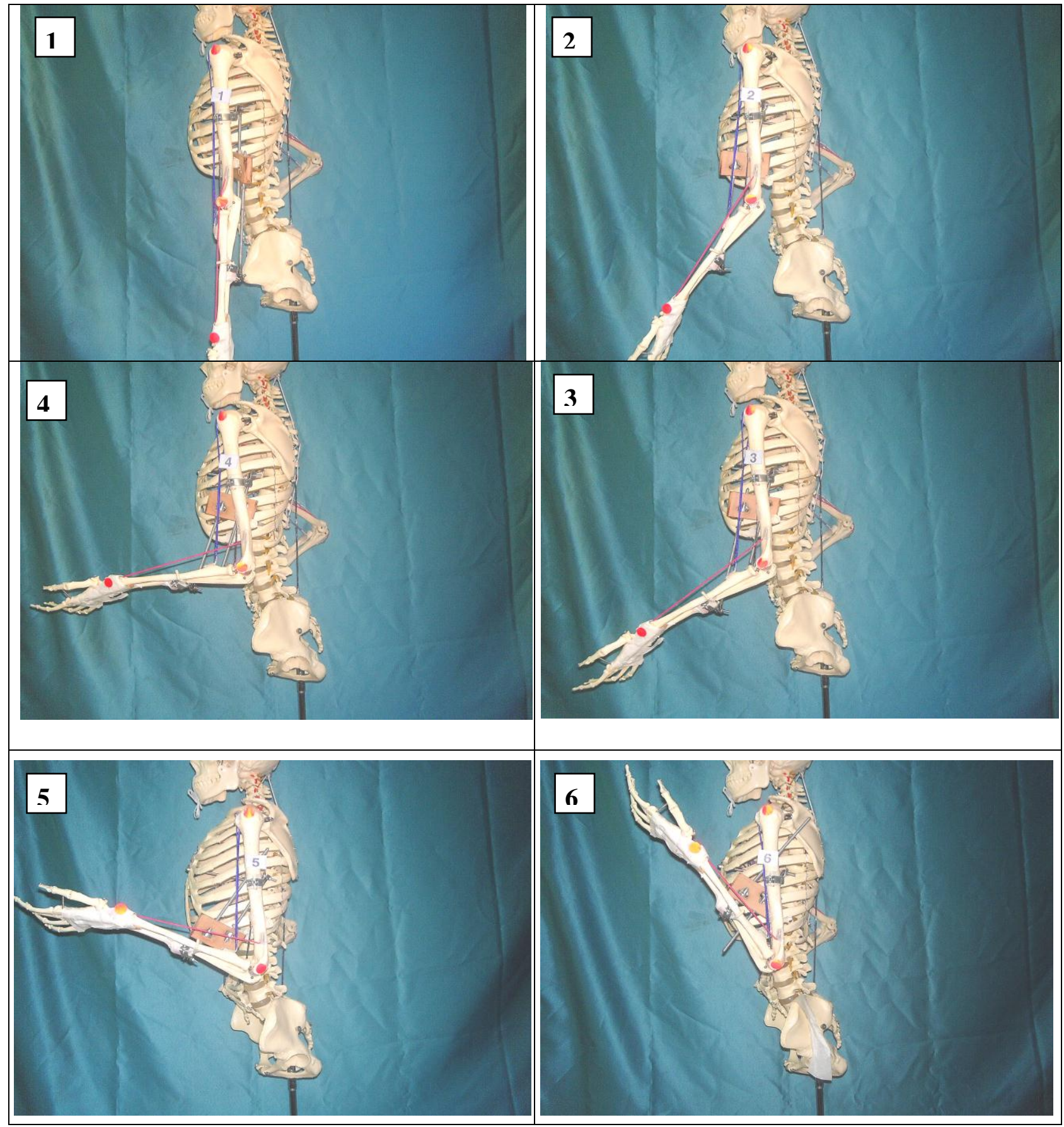

Fourth Phase: Measuring Tension Angles

To measure tension angles for each position, these procedures were followed:

1. Each photo was inputted into computer from camera memory card through a card reader to be transferred quickly with high resolution

2. Photos were categorized according to cadre number in separate files
3. Autocad 2002 software was used to measure tension angles for each muscle with high accuracy

Fifth Phase: Data Processing

To calculate the rotation and stabilization components of the chosen cadres, the following procedures were used:

To calculate the relative muscular force, we applied the following equation:

$\mathrm{F}=\mathrm{PCSA} \times 6$ 
Where $(\mathrm{F})$ is the relative muscle force, (PCSA) is the physiological cross section area (table 1) and (6) is a constant representing the force of each $1 \mathrm{~cm} 2$ of PCSA $(6,7)$

To calculate the rotation and stabilization components, the following equations were applied:

$\Sigma F y=F 1 \sin \Theta 1+F 2 \sin \Theta 2+F 3 \sin \Theta 3$
$\Sigma F x=F 1 \cos \Theta 1+F 2 \cos \Theta 2+F 3 \cos \Theta 3$

Where:

$\Sigma \mathrm{Fy}=$ resultant rotation component on $\mathrm{Y}$ axis

$\Sigma \mathrm{Fx}=$ resultant stabilization component

$\mathrm{F}=$ relative muscular force

$\Theta=$ tension angle

(9)

Table (1)

PCSA for Elbow Flexion Working Muscles

\begin{tabular}{|c|c|c|c|c|c|c|c|c|c|c|c|c|}
\hline \multirow{2}{*}{\multicolumn{2}{|c|}{ Muscle }} & \multicolumn{10}{|c|}{ PCSA $(\mathrm{cm} 2) /$ data source } & \multirow{2}{*}{$\begin{array}{l}\text { Mean } \\
\mathrm{cm} 2\end{array}$} \\
\hline & & $\begin{array}{c}\text { Ref } \\
10 \\
\end{array}$ & $\begin{array}{c}\text { Ref } \\
11 \\
\end{array}$ & $\begin{array}{c}\text { Ref } \\
12 \\
\end{array}$ & $\begin{array}{c}\text { Ref } \\
4\end{array}$ & $\begin{array}{c}\text { Ref } \\
13 \\
\end{array}$ & $\begin{array}{c}\text { Ref } \\
14 \\
\end{array}$ & $\begin{array}{c}\text { Ref } \\
15\end{array}$ & $\begin{array}{c}\text { Ref } \\
16 \\
\end{array}$ & $\begin{array}{c}\text { Ref } \\
17 \\
\end{array}$ & $\begin{array}{c}\text { Ref } \\
5\end{array}$ & \\
\hline \multirow[t]{3}{*}{$1-$} & \multirow{3}{*}{$\begin{array}{c}\text { Biceps Brachii } \\
\text { Long head } \\
\text { Short head } \\
\end{array}$} & & & & & & & & & & & \\
\hline & & 2.5 & 2.01 & 3.12 & & & 2.5 & & 3.21 & 2.78 & 2.89 & 2.72 \\
\hline & & 2.1 & 2.11 & 3.12 & & & 2.1 & & 3.08 & 2.56 & 3.77 & 2.69 \\
\hline $2-$ & Brachialis & 7 & & & & & 7 & 5.4 & & 5.55 & & 6.24 \\
\hline $3-$ & $\begin{array}{l}\text { Brachio } \\
\text { radialis }\end{array}$ & 1.5 & & & 1.33 & 1.33 & 1.5 & 1.2 & & 2.87 & & 1.62 \\
\hline
\end{tabular}

$(10,11,12,4,13,14,15,16,17,5)$

\section{Tools and equipments}

- Protractor for measuring joint angles

- Mechanical device for fixing angles

- Rear curtains

- Suitable light

- Digital camera (BenQ DC E40)

- Tripod

- Card reader

- PC with Autocad 2002 software

\section{Results and Discussion}

Through literature review, analysis of elbow flexion using the biomechanical model, simulation and data collected the researchers concluded the following results:

Table (2)

Measurements of tension angles for elbow flexion working muscles

\begin{tabular}{|c|c|c|c|c|}
\hline \multirow{2}{*}{ Cadre No. } & \multirow{2}{*}{ Angle } & \multicolumn{3}{|c|}{ Tension angles } \\
\cline { 3 - 5 } & & Biceps Brachii & Brachialis & Brachio radialis \\
\hline $1-$ & $180^{\circ}$ & $2^{\mathbf{o}}$ & $0^{\circ}$ & $0^{\mathbf{o}}$ \\
\hline $2-$ & $150^{\circ}$ & $32^{\circ}$ & $30^{\circ}$ & $6^{\mathbf{o}}$ \\
\hline $3-$ & $120^{\circ}$ & $55^{\circ}$ & $47^{\circ}$ & $9^{\mathbf{o}}$ \\
\hline $4-$ & $90^{\circ}$ & $83^{\circ}$ & $77^{\circ}$ & $12^{\mathbf{o}}$ \\
\hline $5-$ & $60^{\circ}$ & $114^{\circ}$ & $106^{\circ}$ & $11^{\circ}$ \\
\hline 6 & $30^{\circ}$ & $150^{\circ}$ & $147^{\circ}$ & $7^{\mathbf{o}}$ \\
\hline
\end{tabular}

Table (2) indicates results of tension angles for elbow flexion working muscles (biceps brachii - brachialis - brachio radialis) in six position from $180^{\circ}$ to $30^{\circ}$ (in the range of motion of the natural joint) with $30^{\circ}$ interval between each two consecutive positions. It is clear that with the continuous movement of elbow flexion, tension angles increase from the first to the last cadre for all muscles, except for brachio radialis as the increase continued until cadre 4 and decreased in 5 and 6 . This answers the first research question. 
Table (3)

Analysis of Elbow Flexion

\begin{tabular}{|c|c|c|c|c|c|c|c|c|c|c|}
\hline $\begin{array}{c}\text { Cadre } \\
\text { No. }\end{array}$ & Angle & Motion & Muscles & $\begin{array}{c}\text { PCSA } \\
\mathrm{cm} 2 \\
\end{array}$ & $\begin{array}{c}\mathrm{F} \\
(\mathrm{kg}) \\
\end{array}$ & $\Theta^{\mathrm{o}}$ & $\begin{array}{c}\text { Stabilization } \\
\text { Fcos } \Theta(\mathrm{kg})\end{array}$ & $\begin{array}{l}\Sigma \mathrm{Fx} \\
(\mathrm{kg}) \\
\end{array}$ & $\begin{array}{c}\text { Rotation } \\
\text { Fsin } \Theta(\mathrm{kg}) \\
\end{array}$ & $\begin{array}{l}\Sigma \mathrm{Fy} \\
(\mathrm{kg})\end{array}$ \\
\hline \multirow{3}{*}{1} & \multirow{3}{*}{$180^{\circ}$} & \multirow{3}{*}{ Flexion } & $\begin{array}{l}\text { Biceps } \\
\text { Brachii }\end{array}$ & 5.41 & 32.46 & $2^{\circ}$ & 32.44 & \multirow{3}{*}{79.6} & 1.13 & \multirow{3}{*}{1.13} \\
\hline & & & Brachialis & 6.24 & 37.44 & $0^{\mathbf{o}}$ & 37.44 & & 0 & \\
\hline & & & $\begin{array}{l}\text { Brachio } \\
\text { radialis }\end{array}$ & 1.62 & 9.72 & $0^{\circ}$ & 9.72 & & 0 & \\
\hline \multirow{3}{*}{2} & \multirow{3}{*}{$150^{\circ}$} & \multirow{3}{*}{ Flexion } & $\begin{array}{l}\text { Biceps } \\
\text { Brachii }\end{array}$ & 5.41 & 32.46 & $32^{\circ}$ & 27.53 & \multirow{3}{*}{69.62} & 17.20 & \multirow{3}{*}{36.09} \\
\hline & & & Brachialis & 6.24 & 37.44 & $30^{\circ}$ & 32.42 & & 18.72 & \\
\hline & & & $\begin{array}{l}\text { Brachio } \\
\text { radialis }\end{array}$ & 1.62 & 9.72 & $6^{\circ}$ & 9.67 & & 0.17 & \\
\hline \multirow{3}{*}{3} & \multirow{3}{*}{$120^{\circ}$} & \multirow{3}{*}{ Flexion } & $\begin{array}{l}\text { Biceps } \\
\text { Brachii }\end{array}$ & 5.41 & 32.46 & $55^{\circ}$ & 18.62 & \multirow{3}{*}{53.75} & 26.59 & \multirow{3}{*}{55.49} \\
\hline & & & Brachialis & 6.24 & 37.44 & $47^{\circ}$ & 25.53 & & 27.38 & \\
\hline & & & $\begin{array}{l}\text { Brachio } \\
\text { radialis }\end{array}$ & 1.62 & 9.72 & $9^{\circ}$ & 9.6 & & 1.52 & \\
\hline \multirow{3}{*}{4} & \multirow{3}{*}{$90^{\circ}$} & \multirow{3}{*}{ Flexion } & $\begin{array}{l}\text { Biceps } \\
\text { Brachii }\end{array}$ & 5.41 & 32.46 & $83^{\circ}$ & 3.95 & \multirow{3}{*}{21.88} & 32.22 & \multirow{3}{*}{70.72} \\
\hline & & & Brachialis & 6.24 & 37.44 & $77^{\circ}$ & 8.42 & & 36.48 & \\
\hline & & & $\begin{array}{l}\text { Brachio } \\
\text { radialis }\end{array}$ & 1.62 & 9.72 & $12^{\circ}$ & 9.51 & & 2.02 & \\
\hline \multirow{3}{*}{5} & \multirow{3}{*}{$60^{\circ}$} & \multirow{3}{*}{ Flexion } & $\begin{array}{l}\text { Biceps } \\
\text { Brachii }\end{array}$ & 5.41 & 32.46 & $114^{\circ}$ & -13.20 & \multirow{3}{*}{-13.98} & 29.65 & \multirow{3}{*}{67.49} \\
\hline & & & Brachialis & 6.24 & 37.44 & $106^{\circ}$ & -10.32 & & 35.99 & \\
\hline & & & $\begin{array}{l}\text { Brachio } \\
\text { radialis }\end{array}$ & 1.62 & 9.72 & $11^{\circ}$ & 9.54 & & 1.85 & \\
\hline \multirow{3}{*}{6} & \multirow{3}{*}{$30^{\circ}$} & \multirow{3}{*}{ Flexion } & $\begin{array}{l}\text { Biceps } \\
\text { Brachii }\end{array}$ & 5.41 & 32.46 & $150^{\circ}$ & -28.11 & \multirow{3}{*}{-49.86} & 16.23 & \multirow{3}{*}{37.8} \\
\hline & & & Brachialis & 6.24 & 37.44 & $147^{\circ}$ & -31.40 & & 20.39 & \\
\hline & & & $\begin{array}{l}\text { Brachio } \\
\text { radialis }\end{array}$ & 1.62 & 9.72 & $7^{\circ}$ & 9.65 & & 1.18 & \\
\hline
\end{tabular}

Figure (3)

Resultant stabilization component and resultant rotation component during elbow flexion

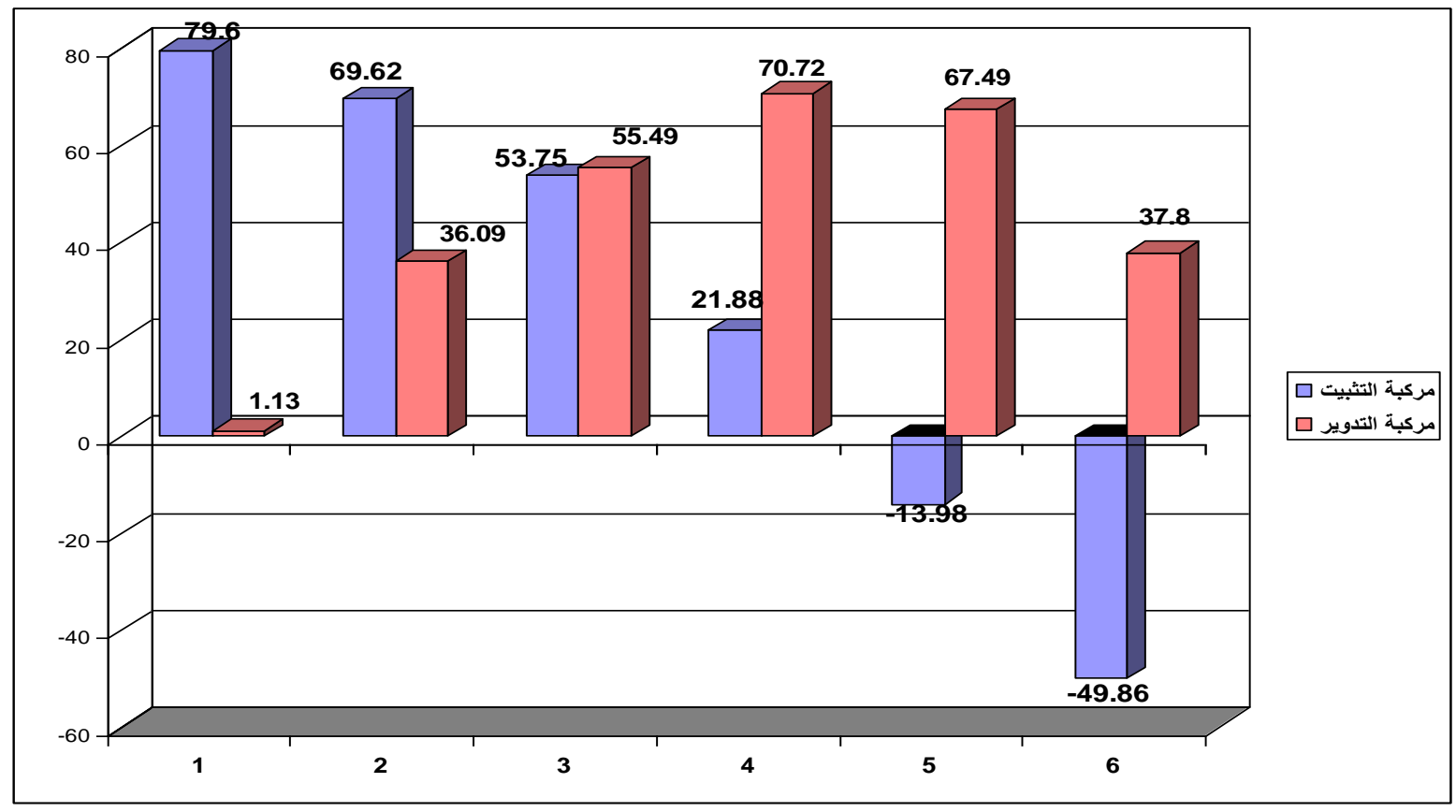


From table (3) and Fig. 3, it is clear that:

Flexion happens due to biceps brachii contraction with a relative force of $32.46 \mathrm{~kg}$, while the same force for brachialis and brachio radialis are $37.44 \mathrm{~kg}$ and $9.72 \mathrm{~kg}$ respectively. With the continuation of motion, the joint angle changes and this leads to changes in tension angles of working muscles. All this leads to changes in rotation and stabilization components.

In cadre (1), joint angle is $180^{\circ}$ in a relatively stable position where rotation component is absent, due to low values of tension angles for biceps brachii, brachialis $(=0)$ and brachio radialis $\left(=2^{\circ}\right)$. Most of the relative force is in stabilization direction as stabilization component $=79.6 \mathrm{~kg}$.

In cadre (2), joint angle is $150^{\circ}$. Tension angles increased for the working muscles $\left(32^{\circ}, 30^{\circ}\right.$ and $6^{\circ}$ for biceps brachii, brachialis and brachio radialis respectively). Forces are transformed into two perpendicular components (stabilization and rotation). Stabilization components for the working muscles were $(27.53 \mathrm{~kg}, 32.42 \mathrm{~kg}$ and $9.67 \mathrm{~kg}$ ) for biceps brachii, brachialis and brachio radialis respectively, while rotation components were $(17.20 \mathrm{~kg}, \quad 18.72 \mathrm{~kg}$ and $0.17 \mathrm{~kg}$ ) for biceps brachii, brachialis and brachio radialis respectively. Resultant stabilization component was $69.62 \mathrm{~kg}$ while resultant rotation component was $36.09 \mathrm{~kg}$.

In cadre (3), joint angle is $120^{\circ}$. Tension angles increased for the working muscles $\left(55^{\circ}, 47^{\circ}\right.$ and $9^{\circ}$ for biceps brachii, brachialis and brachio radialis respectively). Stabilization components for the working muscles were $(18.62 \mathrm{~kg}, 25.53$ $\mathrm{kg}$ and $9.6 \mathrm{~kg}$ ) for biceps brachii, brachialis and brachio radialis respectively, while rotation components were $(26.59 \mathrm{~kg}, 27.38 \mathrm{~kg}$ and $1.52 \mathrm{~kg}$ ) for biceps brachii, brachialis and brachio radialis respectively.when increasing tension angles, Stabilization components decreasing and the rotation component increase. Resultant stabilization component was $53.75 \mathrm{~kg}$ while resultant rotation component was 55.49 $\mathrm{kg}$.

In cadre (4), joint angle is $90^{\circ}$. Tension angles increased for the working muscles $\left(83^{\circ}, 77^{\circ}\right.$ and $12^{\circ}$ for biceps brachii, brachialis and brachio radialis respectively). Stabilization components for the working muscles were $(3.95 \mathrm{~kg}, 8.42 \mathrm{~kg}$ and $9.51 \mathrm{~kg}$ ) for biceps brachii, brachialis and brachio radialis respectively, while rotation components were $(32.22 \mathrm{~kg}, 36.48 \mathrm{~kg}$ and 2.02 $\mathrm{kg}$ ) for biceps brachii, brachialis and brachio radialis respectively. Resultant stabilization component was $21.88 \mathrm{~kg}$ while resultant rotation component was $70.72 \mathrm{~kg}$ (peak value).

In cadre (5), joint angle s $60^{\circ}$. Tension angles increased for the working muscles $\left(114^{\circ}, 106^{\circ}\right.$ and $11^{\circ}$ for biceps brachii, brachialis and brachio radialis respectively). Stabilization components for the working muscles were ($13.2 \mathrm{~kg},-10.32 \mathrm{~kg}$ and $9.54 \mathrm{~kg}$ ) for biceps brachii, brachialis and brachio radialis respectively, while rotation components were $(29.65 \mathrm{~kg}, 35.99 \mathrm{~kg}$ and $1.85 \mathrm{~kg}$ ) for biceps brachii, brachialis and brachio radialis respectively. Resultant rotation component was $37.8 \mathrm{~kg}$ while resultant stabilization component was $-13.98 \mathrm{~kg}$. The minus sign here means that the component is in the direction of dislocation.

In cadre (6), joint angle s $30^{\circ}$. Tension angles increased for the working muscles $\left(150^{\circ}, 147^{\circ}\right.$ and $7^{\circ}$ for biceps brachii, brachialis and brachio radialis respectively). Stabilization components for the working muscles were $-28.11 \mathrm{~kg},-31.40$ $\mathrm{kg}$ and $9.65 \mathrm{~kg}$ ) for biceps brachii, brachialis and brachio radialis respectively, while rotation components were $(16.23 \mathrm{~kg}, 20.39 \mathrm{~kg}$ and 1.18) for biceps brachii, brachialis and brachio radialis respectively. Resultant rotation component was $37.8 \mathrm{~kg}$ and resultant stabilization component was $-49.86 \mathrm{~kg}$. The minus sign here means that the component is in the direction of dislocation.

Accordingly, it is clear that the most stable position of the joint was the first position in cadre (1) where the angle was $180^{\circ}$ as stabilization component was in its peak value $(79.6 \mathrm{~kg})$. This position is naturally stable as there is no motion, followed by the second position in cadre (2) where the angle was $150^{\circ}$ and stabilization component was $(69.62 \mathrm{~kg})$.

Changing joint angles leads to changes in tension angles of working muscles. With the increase of tension angle, the stabilization component decreases. Cadre (6) with angle of $30^{\circ}$ is weakest joint position where injury is highly potential. In this position, the resultant 
stabilization component was in its lowest value $(-49.86 \mathrm{~kg})$, followed by cadre (5) where joint angle was $60^{\circ}$ and resultant stabilization component was $(-13.98 \mathrm{~kg})$. The minus sign in both positions means that it is in the direction of dislocation.

Joint angle of $90^{\circ}$ (cadre 4) is the best angle for motion and coping with resistance as the joint can exert max for during flexion. Resultant rotation component for this angle was in its peak $(70.72 \mathrm{~kg})$ with a suitable resultant stabilization component $(21.88 \mathrm{~kg})$.

\section{Conclusions}

In the light of research aim and procedures, the researchers concluded the following:

1. The most stable position of the joint was the first position in cadre (1) where the angle was $180^{\circ}$. This position is naturally stable as there is no motion, followed by the second position in cadre (2) where the angle was $150^{\circ}$.

2. Joint angle of $90^{\circ}$ (cadre 4 ) is the best angle for motion and coping with resistance as the joint can exert max for during flexion.

3. Cadre (6) with angle of $30^{\circ}$ is weakest joint position where injury is highly potential, followed by cadre (5) where joint angle was $60^{\circ}$.

\section{Recommendations}

1. Using results of this research in directing training for improved performance and injury prevention during similar performances including elbow flexion.

2. Performing more research on other body joints.

3. Applying modeling and simulation and vector analysis in a mechanical study about injuries of body joints in different sports.

\section{References}

1. Hosam El-Din, Talha, Abd El-Rasheed, Said, Kamel, Mostafa \& Slah El-Din, Wafa (1998): Applied Kinesiology, Part one. Markaz AlKetab Press, Cairo - Egypt. PP: 188 - 190. 1st Ed (in Arabic)
2. Hosam El-Din, Talha (1993): Biomechanics: Theories and Practices. Dar Al-Fikr Al-Araby, Cairo - Egypt. P: 124 (in Arabic)

3. Berequa, Mohamed G. \& Roshdy, Mohamed A. (1997):Mechanisms of Backbone Injuries. Monshaat Al-Maaref, Alexandria - Egypt. P: 12 (in Arabic)

4. Lemay, M. A. \& Ceago, P. E. (1996): A dynamic model for simulating movement of elbow, forearm and wrist. Journal of Biomechanics, No. 29, P: 1319-1330.

5.

H.E.J.Veeger:http://www.fbw.vu.nl/research/Lij n_A4/shoulder/vu study_inertia.htm.

6. Berequa, Mohamed G. \& Al-Sokkary, Khairea (2004): Qualitative anatomical analysis for improving training process. Physical Education Conference, Faculty of Physical Education for Men - Alexandria University Egypt (in Arabic).

7. Hasanain, Mohamed S. (2000): Assessment and evaluation in Physical Education. Fikr AlAraby, Cairo - Egypt. P: 118 (in Arabic)

8. Wael Mohamed Abd El-Kader (2005): "Mechanics of the shoulder joint injuries in some Racket Sport players as a base of preventative training programs, Tanta University .

9. Berequa, Mohamed G. \& Al-Sokkary, Khairea (2002): Basic Pinciples of Biomechanics in Sports. Part one, Monshaat AlMaaref, Alexandria - Egypt (in Arabic)

10. Morrey, B. F., An, K. N. , Hui, F. C., Linscheid, R. L. \& Chao, E. Y. (1981): Muscles across the elbow joint: biomechanical analysis. Journal of Biomechanics. P:14

11. Bruce C. Elliott (2007 ): System and modelling errors in motion analysis: Implications for the measurement of the elbow angle in cricket bowling. Journal of BiomechanicsVolume 40, Issue 12, Pages 2679-2685

12. Happe, R. \& van der helm, F. C. T. (1995): The control of shoulder muscle during goal directed movements, an inverse dynamic analysis. Journal of Biomechanics,p:28.

13. Lieber, R. L., Jacobson, M. D., Fazeli, B. M., Abrams, R. A. \& Botte, M. J. (1997): 
Architecture of selected muscles of arm and forearm: anatomy and implications for tendon transfer. The Journal of Hand Surgery, No. 17 ,787-798.

14. Nijuof, E. J. \& Kouwenhoven (2000): Simulation of multi-joint arm movement. In J. M. Winters and P. E. Cargo (eds) Biomechanics and neural control of posture and movement, Springer - Verlag, New York. Journal of Biomechanics,363-372

15. Murray, W. M., Buchanan, T. S. \& Delp, S. L. (2000): the Isometric functional capacity of muscles that cross the elbow,p:33.

16. H. E. J. Veeger, van der helm, F. C. T. van der woude, Pronk G. M \& Rozendal, R. H. (1991): inertia and muscle contraction parameters for musculoskeletal modeling of the shoulder mechanism. Journal of Biomechanics,p:24.

17. H. E. J. Veeger, van der helm: Laboratory for measurement and control,http://www.fbw.vu.nl/research/Lijn_A4/ shoulder/Mayo study_PCSA_k4r.html.

18. Chou, P.H., Lin, C.J., Chou, Y.L., et al. Int J Sport Med (2005):

the relationship between elbow flexion angle and joint loading of the upper extremity during a close-chain exercise, 23(6), 457-462

19. Ellen K. R. EiGhbaum, \& Katharine M. Barthels (2006): Biomechanics: a qualitative approach for studying human movement. 2nd Ed, Burgress Publishing Company. 